\title{
Managed Care
}

\section{Impact of Managed Care on the Treatment, Costs, and Outcomes of Fee-for-Service Medicare Patients with Acute Myocardial Infarction}

\author{
M. Kate Bundorf, Kevin A. Schulman, Judith A. Stafford, \\ Darrell Gaskin, James G. Jollis, and José J. Escarce
}

Objective. To examine the effects of market-level managed care activity on the treatment, cost, and outcomes of care for Medicare fee-for-service acute myocardial infarction (AMI) patients.

Data Sources/Study Setting. Patients from the Cooperative Cardiovascular Project (CCP), a sample of Medicare beneficiaries discharged from nonfederal acute-care hospitals with a primary discharge diagnosis of AMI from January 1994 to February 1996.

Study Design. We estimated models of patient treatment, costs, and outcomes using ordinary least squares and logistic regression. The independent variables of primary interest were market-area managed care penetration and competition. The models included controls for patient, hospital, and other market area characteristics.

Data Collection/Extraction Methods. We merged the CCP data with Medicare claims and other data sources. The study sample included CCP patients aged 65 and older who were admitted during 1994 and 1995 with a confirmed AMI to a nonrural hospital.

Principal Findings. Rates of revascularization and cardiac catheterization for Medicare fee-for-service patients with AMI are lower in high-HMO penetration markets than in low-penetration ones. Patients admitted in high-HMO-competition markets, in contrast, are more likely to receive cardiac catheterization for treatment of their AMI and had higher treatment costs than those admitted in low-competition markets.

Conclusions. The level of managed care activity in the health care market affects the process of care for Medicare fee-for-service AMI patients. Spillovers from managed care activity to patients with other types of insurance are more likely when managed care organizations have greater market power.

Key Words. Managed care penetration, managed care competition, AMI, cost, treatment

The presence of managed care organizations in a health care market may affect health care delivery for both managed care and nonmanaged care patients. Through financial incentives to providers, and by more actively 
managing patient care than other types of insurers, managed care organizations may affect the process, cost, and outcomes of care for plan enrollees (Miller and Luft 1997). Perhaps equally important, however, is the potential for managed care activity to bring about market-level changes in patient care that affect nonmanaged care enrollees as well. Studies of the relationship between managed care penetration in the health care market and expenditures for Medicare fee-for-service enrollees have demonstrated the existence of these types of spillover effects (Welch 1994; Baker 1997, 1999).

Managed care organizations may generate these types of spillover effects by increasing competition in the health care market, changing the structure of the health care delivery system, and changing physician practice patterns (Baker 1997). Studies finding that higher levels of managed care penetration are associated with lower rates of hospital cost inflation (Robinson 1991, 1996; Gaskin and Hadley 1997; Bamezai et al. 1999) and lower physician fees (Hadley et al. 1999) are consistent with competitive effects. Other studies demonstrate the impact of managed care on delivery system structure including hospital capacity (Chernew 1995), hospital admission patterns (Gaskin 1997), the size and composition of the physician workforce (Escarce et al. 1998; Escarce et al. 2000; Polsky et al. 2000), and the adoption and use of medical equipment and technologies (Baker 2001; Baker and Brown 1999; Baker and Phibbs 2000). More recent evidence has linked market-level managed care activity to the process, but not the outcomes of care (Heidenreich et al. 2002).

We gratefully acknowledge financial support from the Robert Wood Johnson Foundation's Changes in Health Care Financing and Organization initiative.

This work was also supported by contract 500-96-P623, sponsored by the Delmarva Foundation for Medical Care, Inc., and the Centers for Medicare and Medicaid Services (formerly the Health Care Financing Administration), U.S. Department of Health and Human Services, both in Baltimore. The contents of this publication do not necessarily reflect the views of the Department of Health and Human Services, nor does mention of trade names, commercial products, or organizations imply endorsement by the U.S. government. The authors assume full responsibility for the accuracy and completeness of the ideas presented. This article is a direct result of the Health Care Quality Improvement Program initiated by the Health Care Financing Administration, which has encouraged identification of quality improvement projects derived from analysis of patterns of care.

Address correspondence to M. Kate Bundorf, Ph.D., M.B.A., M.P.H., Stanford University School of Medicine, HRP Redwood Building, Room 257, Stanford, CA 94305-5405. Kevin A. Schulman, M.D., Judith A. Stafford, M.S., and James G. Jollis, M.D., are with Duke University Medical Center. Darrell Gaskin, Ph.D., is with Johns Hopkins Bloomberg School of Public Health in Baltimore.JoséJ. Escarce, M.D., Ph.D., is with the David Geffen School of Medicine at UCLA and RAND Health Program. 
In this article, we examine the impact of managed care market structure on the treatments, costs, and outcomes of care for Medicare fee-for-service patients with acute myocardial infarction (AMI). By analyzing patients with a specific condition, this study complements existing work documenting the effects of managed care penetration on area-level health care costs and health care market structure by providing evidence on changes in practice patterns.

\section{CONCEPTUAL FRAMEWORK}

The presence of managed care organizations in a health care market creates incentives that affect provider treatment patterns for both managed care and nonmanaged care patients. Managed care organizations control moral hazard in the use of medical care by adopting various types of supply side mechanisms intended to affect the behavior of providers treating patients enrolled in their plans. Administrative mechanisms may include prospective utilization review, case management, and physician gate-keeping (Wickizer and Lessler 2002). Managed care organizations may also adopt financial incentives, such as provider capitation or bonuses, to change provider behavior. Theoretical studies of the effects of supply-side cost sharing on physician behavior (Ellis and McGuire 1993; Ma 1994; Newhouse 1996; Ma and McGuire 1997), physician panel size and the use of quality incentives on treatments patterns (Gaynor, Rebitzer, and Lowell 2001) and the ability of managed care organizations to control referrals to physicians within the network ( $\mathrm{Ma}$ and McGuire 2002) demonstrate the potential for managed care organizations to influence the treatment patterns for patients enrolled in managed care plans.

The actions taken by managed care organizations to influence treatment patterns for their enrollees may also affect the types of treatments received by patients not enrolled in these plans. If physicians adopt only a single practice style for all their patients and the practice style is influenced by the incentives adopted by the managed care plans with which they contract, practice patterns for nonmanaged care patients within a physician practice will resemble those for managed care patients. Empirical evidence of these types of withinpractice spillover effects exists (Glied and Zivin 2002). Managed care organizations may also affect the care received by nonmanaged-care patients through physician learning (Phelps 1992). If physicians treating primarily nonmanaged-care patients are influenced by the practice styles of other physicians in the local health care market who are more intensely involved in managed care, the presence of managed care in a market will affect patients not enrolled in these types of plans. 
The presence of managed care organizations in a health care market may also generate competitive pressure that influences treatment patterns for patients market-wide. In the commercial health insurance market, managed care organizations compete among themselves and with other types of insurers for enrollees. Managed care organizations are able to offer lower premiums than other insurers by either selecting healthier enrollees, adopting more efficient practice styles, or lowering the fees paid to providers. Studies have found that lowering payments to providers is a significant source of savings for managed care organizations (Cutler, McClellan, and Newhouse 2000; Altman, Cutler, and Zeckhauser 2003; Polsky and Nicholson 2003). But lower prices create pressure on providers to reduce costs, and the actions physicians and hospitals take in response to this pressure may affect treatment patterns for all patients.

The structure of the insurance market in an area, including both the level of managed care penetration and the extent of competition among managed care organizations, is likely to affect the magnitude of spillover effects from managed care to nonmanaged care patients. In models of physician learning and the formation of physician practice styles, a particular type of payer must have a significant presence to generate spillover effects. The level of managed care activity in an area will also affect the ability of managed care organizations to reduce provider payments. In areas with a significant managed care presence, providers are more dependent on managed care organizations and these organizations will be more successful in reducing fees.

The level of competition among managed care organizations may also affect the extent of spillover effects. Managed care organizations vary in the mechanisms they adopt to influence provider behavior (Remler et al. 1997). Physician practice pattern spillovers either across physicians within markets or across patients within physician practices are more likely to occur when managed care represents a homogenous influence on practice patterns. The heterogeneity among managed care organizations in the incentives they adopt suggests this is unlikely to be the case in areas served by many different managed care organizations. In addition, monopsony power on the part of these organizations in provider markets is a necessary condition for them to lower prices paid to providers (Pauly 1998). Although studies of the spillover effects of managed care activity have generally focused on managed care penetration, other research suggests that both the level of penetration in an area and the extent of competition among managed care organizations may be important in driving market-level changes in healthcare delivery (Melnick et al. 1992; Gaskin 1997). 
Through these types of mechanisms, we hypothesize that higher health maintenance organization (HMO) market penetration results in less intensive procedure use, shorter length of stay, and lower costs for Medicare fee-forservice patients. The spillover effects of managed care penetration, however, are likely to be greater in market areas where there are fewer managed care organizations because managed care organizations with greater market power are more likely to be able to reduce provider fees as well as influence physician practice patterns. Therefore, we hypothesize that, holding the level of managed care penetration constant, greater competition among managed care organizations will be associated with more intensive procedure use, longer length of stay, and higher costs.

\section{METHODS}

\section{Empirical Models}

We estimated reduced form models of the effects of managed care competition $(\mathrm{MCC})$ and managed care penetration $(\mathrm{MCP})$ on patient treatments, costs, and outcomes, controlling for patient $(\mathrm{P})$, hospital $(\mathrm{H})$, and other market area $(\mathrm{M})$ characteristics:

$$
Y_{i, j, m}=\alpha+\beta_{1} M C P_{m}+\beta_{2} M C C_{m}+\beta_{3} P_{i}+\beta_{4} H_{j}+\beta_{5} M_{m}+\varepsilon_{i, j, m}
$$

where $\mathrm{Y}$ represents a treatment, the cost, or the outcome of care for patient $i$, in hospital $j$, in market area $m$.

\section{Data Sources and Study Sample}

We merged clinical data from the Cooperative Cardiovascular Project (CCP) with Medicare claims for our study. The CCP cohort includes a sample of Medicare beneficiaries $(n=234,769)$ discharged from nonfederal acute-care hospitals with a primary discharge diagnosis of AMI (International Classification of Diseases codes $410 . \times 0$ and $410 . \times 1$ ) between January 1994 and February 1996. Patients were identified using the Medicare National Claims History File associated with patient hospitalizations during overlapping eight-month periods that varied by state. Detailed clinical information was collected for each hospitalization from the patient's medical record (International Classification of Diseases 1991; Ellerbeck et al. 1995; Krumholz et al. 1995). We excluded patients in CCP pilot states due to a lack of claims data. We also excluded patients younger than 65 years of age, those admitted to nonacute care hospitals, and those with multiple discharges in a single day. 
After these exclusions, 206,986 admissions representing 187,007 patients remained.

Next, we constructed episodes of care, defined as an inpatient admission and any transfers to other inpatient institutions, for each patient in each data source. Multiple admissions were considered part of the same episode if the patient had been transferred to or from another acute care hospital or other facility/chronic hospital and the admissions overlapped or fell within one day of each other. We then defined each patient's index episode as the patient's first CCP episode, and excluded subsequent CCP episodes for a particular patient from the analysis. We matched CCP to Medicare patient episodes using episode admission and discharge dates, defining a match as a Medicare episode in which the admission and discharge dates matched exactly, matched within one day, or overlapped the CCP episode. We matched 97 percent of index episodes for eligible CCP patients during this process resulting in a sample of 184,558 patient episodes. We selected patient episodes that took place within a single Metropolitan Statistical Area (MSA) based on the MSA of the provider. ${ }^{1}$ The analysis file included 121,464 eligible patients after these exclusions.

We restricted the study sample to confirmed AMIs based on a CCP indicator $(12,789)$. We also excluded patients whose episode lasted less than three days and were discharged alive, because these patients were likely to be miscoded as true AMIs, as well as patients with episode length of stay exceeding 40 days. Finally, we excluded 10,992 patients with missing data for control variables and 1,676 patients who were transferred during their admission based on information from Medicare claims and for whom we did not have CCP data for their initial hospitalization. The number of observations in our study sample was 93,386 .

\section{Dependent Variables}

The dependent variables in our analysis described the treatments, costs, and outcomes of care for Medicare AMI patients. We examined six different patient treatments and tests during the index episode including any primary intervention, defined as either thrombolytic therapy or primary angioplasty ${ }^{2}$; echocardiogram; stress test, exercise or drug induced; smoking cessation counseling for current smokers; any revascularization, defined as coronary angioplasty or bypass surgery; and cardiac catheterization. Both the CCP and Medicare claims data provided information on whether patients received coronary angioplasty, bypass surgery, and cardiac catheterization during their 
admission, and concordance between the two sources was very high. ${ }^{3}$ Therefore, we identified a patient as having received a procedure if indicated by either source.

Using the Medicare claims, we also created indicators of any revascularization and cardiac catheterization during 30-day and one-year periods subsequent to admission. Because we had Medicare claims only through December 31, 1995, we did not have claims data for a full one-year follow up for patients admitted after December 31, 1994. Thus, we were unable to measure procedure use for these patients for the entire follow-up period. However, we do not anticipate that censoring based on the data of admission biases our results. Nonetheless, we did all analyses using data from follow-up periods on both the full set of patients and the subset with complete follow-up data. We also examined length of stay during the baseline admission.

We measured the cost of each hospital admission by adjusting the total Medicare charges associated with each hospital claim by the institutional cost to charge ratio from 1994 and 1995 HCFA cost reports. Thirty-day and oneyear costs were the sum of costs during the baseline admission and the period subsequent to discharge from the baseline episode. We measured patient outcomes using indicators of mortality within 30 days and one year of the admission date.

\section{Independent Variables}

The independent variables of primary interest were measures from interstudy of managed care penetration and managed care competition in the market area of the patient's hospital of admission, where the market area was defined as the Metropolitan Statistical Area (MSA). Managed care penetration was defined as the proportion of the population enrolled in HMOs, including commercial, Medicare, and Medicaid HMOs, and managed care competition was the number of HMOs serving the market. We used categorical, rather than continuous, measures of managed care penetration (low, $<10$ percent; medium, $\geq 10$ percent and $\leq 25$ percent; and high, $>25$ percent) and managed care competition (low, $<4$; medium, $\geq 4$ and $\leq 10$; and high, $>10$ ) in order to capture nonlinearities in the effects. Patients were concentrated in high-HMO penetration (54 percent) and medium-HMO competition (43 percent) markets (Table 1), most likely due to the exclusion of patients admitted to hospitals in rural areas from the study sample. ${ }^{4}$ In the empirical models, the omitted categories of HMO penetration and HMO competition were the lowest levels. 
Table 1. Descriptive Statistics for Independent Variables

\begin{tabular}{|c|c|c|c|}
\hline & $N$ & Mean & S.D. \\
\hline \multicolumn{4}{|l|}{ Demographic Characteristics } \\
\hline Race - White & 93,386 & 0.892 & - \\
\hline Race - Black & 93,386 & 0.070 & - \\
\hline Race - Other & 93,386 & 0.038 & - \\
\hline Male & 93,386 & 0.509 & - \\
\hline Age $65-69$ & 93,386 & 0.206 & - \\
\hline Age $70-74$ & 93,386 & 0.239 & - \\
\hline Age $75-79$ & 93,386 & 0.214 & - \\
\hline Age $80-84$ & 93,386 & 0.182 & - \\
\hline Age 85-89 & 93,386 & 0.109 & - \\
\hline Age 90 and older & 93,386 & 0.050 & - \\
\hline \multicolumn{4}{|l|}{ Hospital Characteristics } \\
\hline Government & 93,386 & 0.081 & - \\
\hline For-profit & 93,386 & 0.119 & - \\
\hline Not-for-profit & 93,386 & 0.800 & - \\
\hline Teaching & 93,386 & 0.292 & - \\
\hline Bed Size $\leq 150$ & 93,386 & 0.134 & - \\
\hline Bed Size $151-300$ & 93,386 & 0.335 & - \\
\hline Bed Size 301-500 & 93,386 & 0.317 & - \\
\hline Bed Size > $>500$ & 93,386 & 0.214 & - \\
\hline \multicolumn{4}{|l|}{ Managed Care Activity } \\
\hline HMO penetration - low & 93,386 & 0.128 & - \\
\hline HMO penetration - medium & 93,386 & 0.334 & - \\
\hline HMO penetration - high & 93,386 & 0.538 & - \\
\hline HMO competition - low & 93,386 & 0.210 & - \\
\hline HMO competition - medium & 93,386 & 0.425 & - \\
\hline HMO competition - high & 93,386 & 0.365 & - \\
\hline \multicolumn{4}{|l|}{ Market Control Variables } \\
\hline Hospital competition - low & 93,386 & 0.076 & - \\
\hline Hospital competition - medium & 93,386 & 0.393 & - \\
\hline Hospital competition - high & 93,386 & 0.531 & - \\
\hline MSA Size $\leq 500 \mathrm{~K}$ & 93,386 & 0.214 & - \\
\hline MSA Size $>500 K \& \leq 1 \mathrm{M}$ & 93,386 & 0.179 & - \\
\hline MSA Size $>1 \mathrm{M} \& \leq 2.5 \mathrm{M}$ & 93,386 & 0.324 & - \\
\hline MSA Size $>2.5 \mathrm{M}$ & 93,386 & 0.283 & - \\
\hline Unemployment rate & 93,386 & 5.603 & 1.93 \\
\hline MSA average income & 93,386 & 23771.480 & 4,094 \\
\hline Pop $>65$ years & 93,386 & 13.067 & 3.618 \\
\hline AAPCC 1987 & 93,386 & 221.107 & 41.608 \\
\hline Wage Index & 93,386 & 101.046 & 14.617 \\
\hline
\end{tabular}

We controlled for the effect of hospital competition using a HirschmanHerfindahl Index (HHI) based on the number of hospital beds in the MSA. Categorical indicators were defined as follows: $<0.10$ (high), $\geq 0.10$ and 
$\leq 0.35$ (medium), and $>0.35$ (low). Table 1 shows the distribution of patients across the categories. Additional covariates included hospital ownership (public, private nonprofit, and private for-profit), bed size ( $\leq 150$ beds, 151300 beds, 301-500 beds, and $>500$ beds), and teaching status ( $>20$ full-time residents).

Market area characteristics in the models included the population of the metropolitan area $(<500,000 ; 500,000-1$ million; 1 million-2.5 million; and $>2.5$ million); the unemployment rate, as a proxy for the level of insurance coverage in the market; per capita income, to control for market level effects of income on demand for health care; the proportion of the population $\geq 65$, to control for the influence of the Medicare program on market level treatment patterns; and the logarithm of the HCFA hospital wage index, to control for hospital input prices. The 1987 county-level AAPCC, aggregated to the MSA level weighted by the county population, controls for differences across local areas in practice style that may have affected HMO entry and growth.

Last, the detailed clinical information in the $\mathrm{CCP}$ allowed us to control for patient illness severity at the time of presentation (Krumholz et al. 2001). The patient-level variables in the empirical model included demographic characteristics, coronary disease and myocardial infarction severity, other illnesses, and functional status. ${ }^{5}$

\section{Model Estimation}

We used binary logistic regression to estimate models with binary dependent variables. The analysis of smoking cessation counseling was restricted to current smokers; other analyses were based on the entire study sample. Our analyses of treatments for which we obtained information from Medicare claims about procedure use subsequent to the index admission (i.e., revascularization and cardiac catheterization) were conducted using the entire sample of patients for whom data were available for each follow-up period, and repeated using a restricted sample of patients for whom data were available for the entire year following discharge. We report results from both samples for procedure use upon admission, but only the results from the subset of patients for whom we had data for the entire year of follow-up for the subsequent periods. ${ }^{6}$ We used ordinary least squares (OLS) to estimate the model of patient length of stay, using a log transformation to adjust the skewed dependent variable. Models of patient costs, including admission costs and 30-day, and one-year follow-up costs were also estimated using OLS with a log transformed dependent variable. The estimated standard errors of the 
coefficients are adjusted for potential correlation in the error term across patients within hospitals using a variation of the standard heteroskedasticityconsistent estimator of the covariance matrix (White 1980; Rogers 1993). In the tables, we present only a subset of coefficients from our models, although all models include the full set of patient, hospital, and market control variables discussed above. For models estimated using binary logistic regression, odds ratios are shown.

\section{RESULTS}

\section{Descriptive Data}

Table 2 presents descriptive statistics for the dependent variables. Of the 17.9 percent of patients receiving any primary intervention, more than 90 percent received thrombolytics. Sixty-one percent of patients underwent an echocardiogram and 12.2 percent received a stress test. Of the 15.3 percent of patients identified as current smokers, only 34.0 percent had documentation of smoking cessation counseling in the medical record. The proportion of patients who received a revascularization procedure increased from 30.2 percent during the index admission to 36.7 percent within a year subsequent to admission to the index episode. Twenty-three percent of patients received coronary angioplasty, 17.1 percent received bypass surgery, and 3.0 percent received both procedures within a year of their episode admission date. Rates of cardiac catheterization also increased during the follow-up period, from 46.3 percent during the baseline admission to 51.6 percent within a year following discharge. Correspondingly, patients incurred incremental costs during the follow-up period. Patient costs averaged $\$ 13,287$ during the index episode and increased to $\$ 19,978$ during the year following discharge from the baseline admission. Mortality rates for the AMI patients in our study increased from 19.1 percent within 30 days to 32.6 percent within one year from admission.

\section{Multivariate Models: Patient Treatments and Length of Stay}

We find evidence of spillover effects from managed care activity on the treatment of fee-for-service Medicare AMI patients, although the effects differ across the treatments we studied (Table 3). Competition from HMOs rather than penetration was associated with receiving a primary intervention. Patients admitted to hospitals in medium- and high-HMO-competition markets were more likely to receive a primary intervention than those 
Table 2. Treatments, Costs, and Outcomes for Medicare AMI Patients

\begin{tabular}{|c|c|c|c|}
\hline Variable & $N$ & Mean & S.D. \\
\hline \multicolumn{4}{|l|}{ Treatments } \\
\hline $\begin{array}{l}\text { Any primary intervention (Thrombolytic Therapy or } \\
\text { Primary PTCA) }\end{array}$ & 93,386 & 0.179 & - \\
\hline Echo test & 93,386 & 0.609 & - \\
\hline Stress test & 93,386 & 0.122 & - \\
\hline Smoking cessation counseling for current smokers & 14,245 & 0.340 & - \\
\hline Length of stay & 93,386 & 8.521 & 5.768 \\
\hline Any revascularization - baseline admission & 93,386 & 0.302 & - \\
\hline $\begin{array}{l}\text { Any revascularization - during baseline or within } 30 \text { days } \\
\text { of discharge }\end{array}$ & 93,386 & 0.320 & - \\
\hline $\begin{array}{l}\text { Any revascularization - during baseline or within } 1 \text { year of } \\
\text { discharge }\end{array}$ & 58,025 & 0.367 & - \\
\hline Cardiac catheterization - baseline admission & 93,386 & 0.463 & - \\
\hline $\begin{array}{l}\text { Cardiac catheterization - during baseline or within } 30 \text { days } \\
\text { of discharge }\end{array}$ & 93,386 & 0.476 & - \\
\hline $\begin{array}{l}\text { Cardiac catheterization - during baseline or within } 1 \text { year } \\
\text { of discharge }\end{array}$ & 58,025 & 0.516 & - \\
\hline \multicolumn{4}{|l|}{ Cost } \\
\hline Admission costs & 93,386 & $\$ 13,287$ & 20,602 \\
\hline 30 day costs & 93,385 & $\$ 14,094$ & 20,801 \\
\hline 1 year costs & 56,340 & $\$ 19,978$ & 29,048 \\
\hline \multicolumn{4}{|l|}{ Outcomes } \\
\hline 30 day mortality & 93,386 & 0.191 & - \\
\hline 1 year mortality & 93,386 & 0.326 & - \\
\hline
\end{tabular}

Notes: The study sample includes CCP patients with a confirmed AMI admitted to a nonrural, acute care hospital during 1994 and early 1995. Cost data is derived from charges from Medicare claims for the admission, adjusted by the hospital's cost-to-charge ratio.

admitted in low-competition markets. Similarly, length of stay was shorter for patients admitted to hospitals in high-HMO-competition markets than for those admitted to hospitals in low-HMO-competition markets, but HMO penetration had no effect. Neither managed care penetration nor managed care competition had a statistically significant effect on the probability that a patient received an echocardiogram or a stress test. Patients in high-HMOpenetration markets were more likely to receive smoking counseling than those in low-penetration markets, consistent with the hypothesis that managed care promotes the use of preventive interventions. However, current smokers in high-HMO-competition markets were less likely to receive smoking cessation counseling than those in low-HMO-competition markets, although the effect was marginally statistically significant $(p \leq .06)$. 
Table 3. Effects of HMO Penetration and HMO Competition on Treatments

\begin{tabular}{|c|c|c|c|c|c|}
\hline & $\begin{array}{c}\text { Any } \\
\text { Primary }\end{array}$ & Echo & Stress & $\begin{array}{c}\text { Smoking } \\
\text { Cessation } \\
\text { Counseling }\end{array}$ & $\ln (L O S)$ \\
\hline HMO penetration - medium & $\begin{array}{r}1.067 \\
{[1.16]}\end{array}$ & $\begin{array}{c}0.901 \\
{[1.29]}\end{array}$ & $\begin{array}{c}0.863 \\
{[1.41]}\end{array}$ & $\begin{array}{c}1.066 \\
{[0.71]}\end{array}$ & $\begin{array}{c}-0.015 \\
{[0.80]}\end{array}$ \\
\hline HMD penetration - high & $\begin{array}{c}1.014 \\
{[0.25]}\end{array}$ & $\begin{array}{c}0.925 \\
{[0.96]}\end{array}$ & $\begin{array}{c}0.943 \\
{[0.55]}\end{array}$ & $\begin{array}{l}1.322^{* * *} \\
{[3.07]}\end{array}$ & $\begin{array}{c}-0.006 \\
{[0.29]}\end{array}$ \\
\hline HMO competition - medium & $\begin{array}{l}1.125^{\text {** }} \\
{[2.58]}\end{array}$ & $\begin{array}{c}0.992 \\
{[0.13]}\end{array}$ & $\begin{array}{c}0.961 \\
{[0.48]}\end{array}$ & $\begin{array}{r}1.017 \\
{[0.24]}\end{array}$ & $\begin{array}{c}-0.072 * * \\
{[4.37]}\end{array}$ \\
\hline HMO competition - high & $\begin{array}{l}1.185^{* * *} \\
{[2.76]}\end{array}$ & $\begin{array}{r}1.125 \\
{[1.42]}\end{array}$ & $\begin{array}{r}1.015 \\
{[0.13]}\end{array}$ & $\begin{array}{c}0.84 \\
{[1.92]}\end{array}$ & $\begin{array}{c}-0.120^{* * *} \\
{[5.40]}\end{array}$ \\
\hline Hospital competition - medium & $\begin{array}{r}1.093 \\
{[1.39]}\end{array}$ & $\begin{array}{c}1.014 \\
{[0.15]}\end{array}$ & $\begin{array}{c}1.046 \\
{[0.40]}\end{array}$ & $\begin{array}{r}1.017 \\
{[0.17]}\end{array}$ & $\begin{array}{c}0.038 \\
{[1.84]}\end{array}$ \\
\hline Hospital competition - high & $\begin{array}{l}1.341^{\text {** }} \\
{[3.16]}\end{array}$ & $\begin{array}{c}0.899 \\
{[0.85]}\end{array}$ & $\begin{array}{c}0.905 \\
{[0.66]}\end{array}$ & $\begin{array}{c}0.889 \\
{[0.85]}\end{array}$ & $\begin{array}{c}-0.055 \\
{[1.87]}\end{array}$ \\
\hline Government & $\begin{array}{r}1.031 \\
{[0.58]}\end{array}$ & $\begin{array}{r}0.935 \\
{[1.03]}\end{array}$ & $\begin{array}{c}0.94 \\
{[0.74]}\end{array}$ & $\begin{array}{c}1.03 \\
{[0.38]}\end{array}$ & $\begin{array}{c}-0.027 \\
{[1.47]}\end{array}$ \\
\hline For-Profit & $\begin{array}{c}0.968 \\
{[0.76]}\end{array}$ & $\begin{array}{l}0.855^{* * *} \\
{[2.71]}\end{array}$ & $\begin{array}{l}0.774^{* * *} \\
{[3.31]}\end{array}$ & $\begin{array}{l}0.825^{\text {** }} \\
{[2.87]}\end{array}$ & $\begin{array}{l}0 \\
{[0.03]}\end{array}$ \\
\hline Teaching & $\begin{array}{l}0.923^{*} \\
{[2.02]}\end{array}$ & $\begin{array}{c}0.999 \\
{[0.03]}\end{array}$ & $\begin{array}{l}1.134^{*} \\
{[2.06]}\end{array}$ & $\begin{array}{c}0.982 \\
{[0.31]}\end{array}$ & $\begin{array}{c}0.023 \\
{[1.84]}\end{array}$ \\
\hline Bed Size 151-300 & $\begin{array}{r}0.949 \\
{[1.31]}\end{array}$ & $\begin{array}{l}1.144^{* * *} \\
{[2.68]}\end{array}$ & $\begin{array}{l}1.255^{\text {** }} \\
{[3.49]}\end{array}$ & $\begin{array}{l}1.082 \\
{[1.18]}\end{array}$ & $\begin{array}{l}0.087^{* * *} \\
{[5.86]}\end{array}$ \\
\hline Bed Size 301-500 & $\begin{array}{l}0.866^{* * *} \\
{[3.41]}\end{array}$ & $\begin{array}{c}1.04 \\
{[0.71]}\end{array}$ & $\begin{array}{l}1.159^{*} \\
{[2.05]}\end{array}$ & $\begin{array}{l}1.184^{*} \\
{[2.47]}\end{array}$ & $\begin{array}{l}0.114^{* *} \\
{[7.48]}\end{array}$ \\
\hline Bed Size $>500$ & $\begin{array}{l}0.747^{* * *} \\
{[5.51]}\end{array}$ & $\begin{array}{c}0.949 \\
{[0.79]}\end{array}$ & $\begin{array}{c}1.122 \\
{[1.32]}\end{array}$ & $\begin{array}{r}1.063 \\
{[0.71]}\end{array}$ & $\begin{array}{l}0.119^{* *} \\
{[6.69]}\end{array}$ \\
\hline $\begin{array}{l}\text { Observations } \\
\text { Pseudo R2/Adjusted R2 }\end{array}$ & $\begin{array}{r}93,386 \\
0.136\end{array}$ & $\begin{array}{r}93,386 \\
0.033\end{array}$ & $\begin{array}{r}93,386 \\
0.063\end{array}$ & $\begin{array}{r}14,245 \\
0.042\end{array}$ & $\begin{array}{r}93,386 \\
0.143\end{array}$ \\
\hline
\end{tabular}

Robust z/t-statistics in brackets.

*significant at $5 \%$; **significant at $1 \%$.

Models with binary dependent variables estimated using maximum likelihood logit-odds ratios shown.

Models with continous dependent variables estimated using OLS-coefficients shown.

For revascularization, we find that higher levels of HMO penetration were associated with lower procedure rates, although the results were sensitive to the choice of the sample (Table 4). Results from all patients for whom data were available for the index admission suggest that a negative effect of HMO penetration on revascularization rates was not statistically significant. The results for a restricted sample of patients for whom data were available for the 


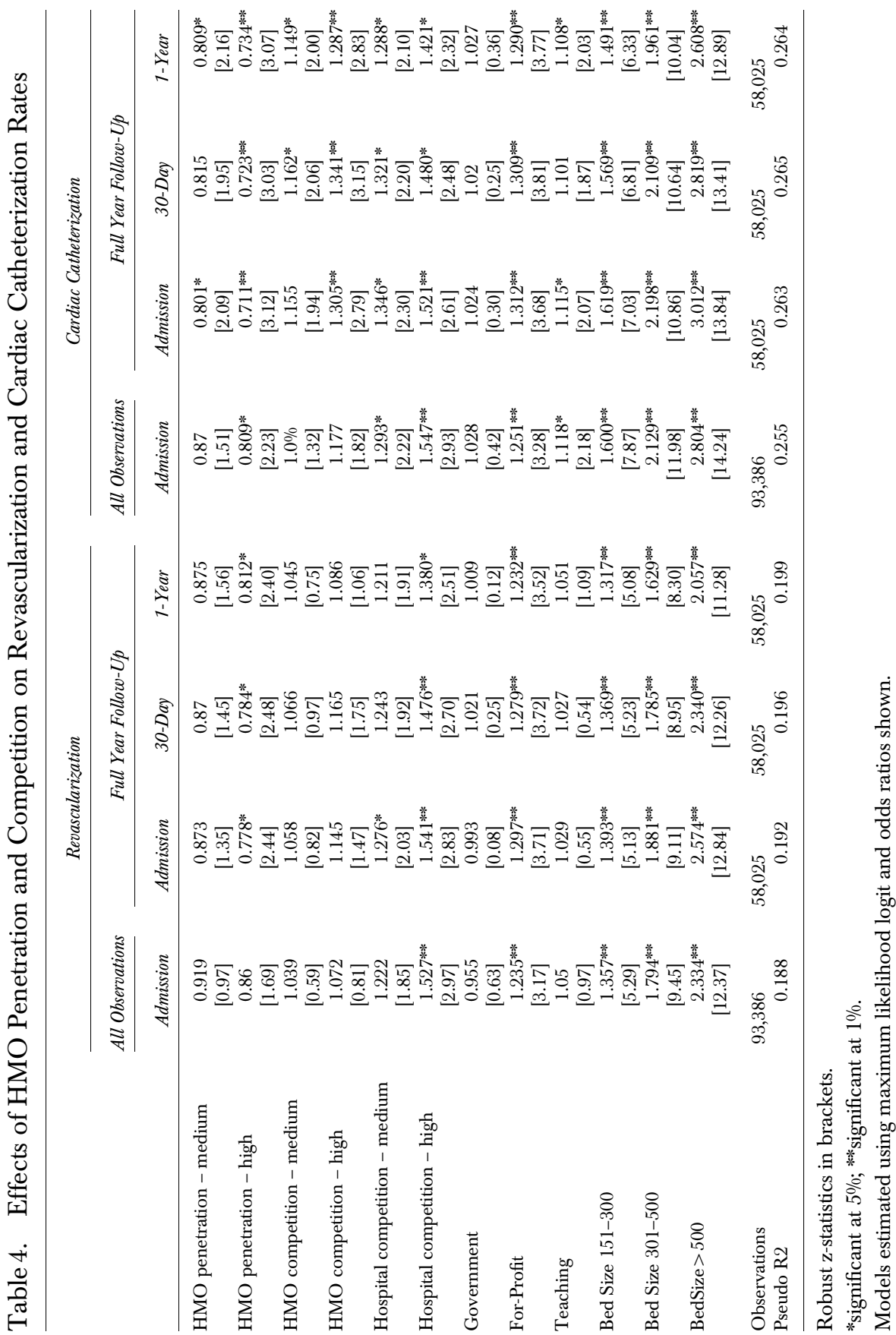


entire year of follow-up, in contrast, indicate that revascularization rates were lower in markets with greater HMO penetration from the index admission throughout the entire follow-up period. The results indicate that, for patients in our sample, a change from a low- to high-penetration market was associated with a 4-percentage point reduction in the probability of revascularization on average and a change from low- to high-HMO-competition was associated with a 2-percentage point increase in the probability of revascularization. ${ }^{7}$ For cardiac catheterization, we find that procedure rates were lower in markets with greater $\mathrm{HMO}$ penetration and higher in markets characterized by greater HMO competition. However, the point estimate of the effect of high HMO competition, although positive, was not statistically significant in the model of procedure use upon admission using data from all available observations (Table 4). ${ }^{8}$ Once again, a change from a low- to high-HMO-penetration market was associated with a 4-percentage point reduction in the probability of catheterization and an increase from low to high levels of HMO competition was associated with 2-percentage point increase in the likelihood of catheterization.

Hospital competition also plays a role in patient treatments for AMI, particularly for rates of invasive procedures. Patients admitted in highhospital-competition markets were more likely to receive any primary intervention (Table 3), cardiac catheterization, and any revascularization (Table 4) than those admitted in low-competition markets. Greater competition among hospitals, however, did not have a statistically significant effect on less invasive treatments including echocardiogram, stress test, and smoking cessation counseling (Table 3).

Hospital characteristics were strongly associated with the process of care for AMI. Patients admitted to for-profit and larger hospitals were more likely to receive any revascularization as well as cardiac catheterization (Table 4). Although for-profit status was associated with a higher probability of receiving these intensive procedures relative to private, not-for-profit hospitals, it had no effect on patient length of stay and was associated with a lower probability of receiving an echocardiogram, stress test, and smoking cessation counseling (Table 3). Admission to a teaching hospital was associated with a greater likelihood of receiving a stress test as well as cardiac catheterization and a lower likelihood of receiving a primary intervention (Table 3). However, teaching status had no effect on the other treatments we studied. Although the magnitude of the positive effect of hospital size on procedure rates diminishes during the year following admission, the existence of positive effects of the characteristics of the patient's index admission hospital on procedure rates 
throughout the period suggests that differences in treatment due to hospital of admission persist over time.

\section{Multivariate Models: Patient Costs and Outcomes}

We found that HMO competition had a stronger effect on patient costs than HMO penetration (Table 5). Specifically, costs were significantly higher for patients admitted to high-HMO-competition markets relative to those

Table 5. Effects of HMO Penetration and Competition on Costs and Outcomes

\begin{tabular}{|c|c|c|c|c|c|}
\hline & \multicolumn{3}{|c|}{ Costs } & \multicolumn{2}{|c|}{ Outcomes } \\
\hline & $\ln ($ admission) & $\ln (30 d a y)$ & $\ln (l$ year $)$ & $\begin{array}{c}\text { 30-Day } \\
\text { Mortality }\end{array}$ & $\begin{array}{c}\text { 1-Year } \\
\text { Mortality }\end{array}$ \\
\hline HMO penetration - medium & $\begin{array}{r}-0.007 \\
{[0.28]}\end{array}$ & $\begin{array}{r}0.001 \\
{[0.05]}\end{array}$ & $\begin{array}{r}-0.011 \\
{[0.39]}\end{array}$ & $\begin{array}{r}1.063 \\
{[1.33]}\end{array}$ & $\begin{array}{r}1.027 \\
{[0.68]}\end{array}$ \\
\hline HMO penetration - high & $\begin{array}{c}-0.035 \\
{[1.26]}\end{array}$ & $\begin{array}{c}-0.024 \\
{[0.89]}\end{array}$ & $\begin{array}{c}-0.054 \\
{[1.81]}\end{array}$ & $\begin{array}{l}1.022 \\
{[0.45]}\end{array}$ & $\begin{array}{l}1.007 \\
{[0.17]}\end{array}$ \\
\hline HMO competition - medium & $\begin{array}{r}0.027 \\
{[1.25]}\end{array}$ & $\begin{array}{c}0.029 \\
{[1.38]}\end{array}$ & $\begin{array}{c}0.013 \\
{[0.60]}\end{array}$ & $\begin{array}{c}1.06 \\
{[1.54]}\end{array}$ & $\begin{array}{l}1.043 \\
{[1.41]}\end{array}$ \\
\hline HMO competition - high & $\begin{array}{l}0.111^{* * *} \\
{[3.02]}\end{array}$ & $\begin{array}{l}0.119^{* * *} \\
{[3.32]}\end{array}$ & $\begin{array}{c}0.082^{*} \\
{[2.46]}\end{array}$ & $\begin{array}{c}0.994 \\
{[0.12]}\end{array}$ & $\begin{array}{c}1.01 \\
{[0.25]}\end{array}$ \\
\hline Hospital competition - medium & $\begin{array}{c}0.066 \\
{[1.92]}\end{array}$ & $\begin{array}{r}0.057 \\
{[1.73]}\end{array}$ & $\begin{array}{r}0.057 \\
{[1.56]}\end{array}$ & $\begin{array}{r}1.062 \\
{[1.30]}\end{array}$ & $\begin{array}{c}1.02 \\
{[0.45]}\end{array}$ \\
\hline Hospital competition - high & $\begin{array}{c}-0.013 \\
{[0.24]}\end{array}$ & $\begin{array}{c}-0.019 \\
{[0.37]}\end{array}$ & $\begin{array}{c}0.028 \\
{[0.54]}\end{array}$ & $\begin{array}{l}1.024 \\
{[0.34]}\end{array}$ & $\begin{array}{c}0.983 \\
{[0.29]}\end{array}$ \\
\hline Government & $\begin{array}{c}0.021 \\
{[0.99]}\end{array}$ & $\begin{array}{c}0.025 \\
{[1.21]}\end{array}$ & $\begin{array}{c}0.032 \\
{[1.60]}\end{array}$ & $\begin{array}{l}1.085 \\
{[1.91]}\end{array}$ & $\begin{array}{l}1.079^{*} \\
{[2.50]}\end{array}$ \\
\hline For-Profit & $\begin{array}{l}0.032 \\
{[1.65]}\end{array}$ & $\begin{array}{c}0.034 \\
{[1.79]}\end{array}$ & $\begin{array}{c}0.052^{*} \\
{[2.58]}\end{array}$ & $\begin{array}{r}0.969 \\
{[0.86]}\end{array}$ & $\begin{array}{l}1.008 \\
{[0.26]}\end{array}$ \\
\hline Teaching & $\begin{array}{l}0.096^{* * *} \\
{[4.84]}\end{array}$ & $\begin{array}{l}0.095^{* * *} \\
{[4.93]}\end{array}$ & $\begin{array}{l}0.102^{* * *} \\
{[5.01]}\end{array}$ & $\begin{array}{l}0.927^{*} \\
{[2.55]}\end{array}$ & $\begin{array}{c}0.96 \\
{[1.64]}\end{array}$ \\
\hline Bed Size 151-300 & $\begin{array}{l}0.056^{* * *} \\
{[3.29]}\end{array}$ & $\begin{array}{l}0.049^{* *} \\
{[2.90]}\end{array}$ & $\begin{array}{l}0.055^{\text {*** }} \\
{[2.86]}\end{array}$ & $\begin{array}{l}0.882^{* * *} \\
{[3.63]}\end{array}$ & $\begin{array}{l}0.937^{*} \\
{[2.18]}\end{array}$ \\
\hline Bed Size 301-500 & $\begin{array}{l}0.089 * * \\
{[4.20]}\end{array}$ & $\begin{array}{l}0.075^{* * *} \\
{[3.60]}\end{array}$ & $\begin{array}{l}0.083^{* * *} \\
{[3.46]}\end{array}$ & $\begin{array}{l}0.820^{* *} \\
{[5.31]}\end{array}$ & $\begin{array}{l}0.894^{* * *} \\
{[3.49]}\end{array}$ \\
\hline Bed Size > 500 & $\begin{array}{l}0.180^{* * *} \\
{[7.65]}\end{array}$ & $\begin{array}{l}0.156^{* *} \\
{[6.69]}\end{array}$ & $\begin{array}{l}0.156^{\text {*** }} \\
{[6.10]}\end{array}$ & $\begin{array}{l}0.770^{* * *} \\
{[6.21]}\end{array}$ & $\begin{array}{l}0.835^{* *} \\
{[5.08]}\end{array}$ \\
\hline Observations & 93,386 & 93,385 & 56,340 & 93,386 & 93,386 \\
\hline Adjusted/Pseudo R2 & 0.140 & 0.140 & 0.130 & 0.320 & 0.266 \\
\hline
\end{tabular}

Robust $\mathrm{t} / \mathrm{z}$-statistics in brackets.

*significant at $5 \%$;

***ignificant at $1 \%$.

Cost models estimated using OLS and coefficients shown.

Outcome models estimated using maximum likelihood logit and odds ratios shown. 
admitted to low-HMO-competition markets. Admission costs were 11 percent higher and one-year costs were 8 percent higher. Hospital characteristics were strongly associated with treatment costs (Table 5). In particular, treatment costs were higher for patients initially admitted to teaching hospitals and larger hospitals.

The spillover effects of managed care activity had little relationship with health outcomes measured by mortality rates (Table 5). The characteristics of the hospital to which the patient was admitted for the baseline admission, in contrast, had a strong relationship with mortality rates. Mortality rates were higher for patients initially admitted to government hospitals (one-year) and lower for those initially admitted to teaching hospitals (30-day and 6-month). Mortality rates were lower for patients admitted to larger hospitals.

\section{CONCLUSIONS}

This study makes two important contributions to the body of evidence demonstrating that managed care organizations are driving market-level changes in the delivery of health care. First, the results provide evidence that managed care activity is associated with treatments and the cost of care for feefor-service Medicare patients with AMI. Prior studies have found that managed care penetration affects the availability of technology in a market and the average cost of care for nonmanaged care patients. This study provides evidence that spillover effects influence the types of care that individual patients receive for specific conditions. Our results suggest that higher levels of managed care penetration are associated with reductions in the utilization of costly procedures such as revascularization and cardiac catheterization and increases in the use of low-cost preventive services such as smoking cessation counseling in fee-for-service patients.

Second, the results suggest that the spillover effects generated by managed care penetration are eroded somewhat by competition among managed care organizations, particularly the effects for costly procedures. Cardiac catheterization rates decreased with the level of HMO penetration in the market and increased with the level of HMO competition. Point estimates for revascularization rates revealed similar effects, although the effects of HMO competition were not statistically significant at conventional levels. These results are consistent with the notion that managed care organizations must have significant market power in order to engender marketwide changes in health care delivery. Greater market power improves the bargaining 
position of managed care organizations, allowing them to extract steeper discounts from providers. Lower provider payments, in turn, drive changes in practice patterns and technology availability, which spill over onto nonmanaged care patients.

In most cases, our results are consistent with our hypothesized effects, particularly for resource-intensive procedures. In the case of length of stay, in contrast, we found that decreases in length of stay were more strongly associated with the level of competition among HMOs within the market than the level of HMO penetration. While not consistent with our hypotheses, this indicates that managed care organizations are able to drive changes in length of stay independent of their market power, potentially due to a similarity among these organizations in their focus on length of stay as a source of cost reductions.

Although market characteristics are important in determining patient treatments and costs, the characteristics of the hospital to which the patient was admitted affected outcomes as well. Thus, considerable within-market variation exists in treatment patterns and quality of care.

Our study has several limitations. The analyses were based on crosssectional variation across markets in managed care activity, raising questions about whether the relationship between managed care activity and outcomes that we observed is causal. The primary concern is that managed care market structure may be endogenous with respect to the outcomes we studied. However, this is unlikely for several reasons. First, we studied practice patterns for a single condition, myocardial infarction. Entry decisions of managed care organizations are unlikely to be driven by local practice patterns for one condition. Nonetheless, if practice patterns are correlated across conditions and are related to entry decisions, the possibility of endogeneity remains. Second, our models include the 1987 AAPCC to control for variation acrossmarket areas in historical costs of care for Medicare beneficiaries, which should capture variations in practice patterns across many conditions. This reduces the possibility that our estimates are biased by entry of managed care organizations into markets based on these patterns. Finally, the available evidence suggests that demand for managed care organizations was greatest in markets in which health care costs were high or increasingly rapidly (Goldberg and Greenburg 1981; Welch 1994; Porell and Wallack 1990). If this were the case, any endogeneity bias would be in the opposite direction from our results.

In addition, although our results do not provide evidence that changes in treatment patterns affected patient mortality, changes in treatment patterns may have affected health outcomes related to quality of life that we were 
unable to measure. For example, our data provide no information on the prevalence of symptoms, such as angina, following myocardial infarction. A comparison of the United States and Canada found that higher rates of diagnostic and therapeutic interventions in the United States after myocardial infarction were not associated with differential patient mortality between the two countries but were associated with lower rates of activity-limiting angina (Rouleau et al. 1993).

Finally, our analyses were not designed to identify the precise mechanisms driving changes in treatment patterns and costs, although it is likely that they are driven by changes in practice patterns or changes in the availability of technology.

Our results have important implications for both the Medicare program and other nonmanaged-care patients. Patients with other types of insurance may experience the benefits as well as the costs of practice patterns generally associated with managed care plans. If managed care plans promote more efficient practice styles by lowering costs and improving quality, all types of patients in a market may benefit through spillovers. However, if managed care reduces costs at the expense of quality of care and this conflicts with the objectives of other payers in a market, careful monitoring of quality of care will be necessary.

\section{NOTES}

1. More than 90 percent of the episodes excluded based on the single MSA inclusion criteria took place in rural areas or were transfers between rural and urban areas. Access to emergency and cardiac care facilities varies between rural and urban areas and managed care organizations are less likely to enter and expand in rural areas. Thus, we believe these exclusions are necessary to eliminate potential confounding between patterns of care typical of rural areas and managed care penetration. In the case of transfers between MSAs, the issue was how to attribute the market characteristics for the episode of care. For example, the level of managed care penetration in the MSA of the first admission may affect the probability of a transfer, while the level of managed care penetration in the second may affect the types of treatments ultimately received. We excluded these admissions to avoid introducing measurement error into our analysis, biasing downward our estimates of the effects of managed care activity.

2. Primary angioplasty is defined as coronary angioplasty within 60 to 90 minutes of arrival.

3. Indicators based on Medicare claims and CCP data conflict for 3.7 percent, 2.6 percent, and 5.7 percent of admissions for coronary angioplasty, bypass surgery, and cardiac catheterization, respectively. For each procedure, the Medicare claims data 
were more likely to indicate the patient had received the procedure when the CCP did not than vice-versa.

4. Our study dataset included patients admitted to hospitals in 238 unique MSAs in 39 states.

5. Patient level control variables include sex, race, SBP on arrival, pulse rate on arrival, MI location, history of CHF, shock, prior MI, history of bypass surgery, smoking status, history of diabetes mellitus, history of hypertension, history of cerebrovascular disease, renal function, history of dementia, cardiac arrest, ventricular tachycardia/fibrillation on arrival, COPD, history of coronary angioplasty, history of terminal illness, and history of PVD.

6. Results from the entire set of patients for whom data were available for the follow-up periods are available upon request.

7. The marginal effects are the difference between the average predicted probability of procedure use for all observations in the sample holding the HMO activity variables constant at the levels indicated and are calculated using the model estimated on the sample with full year follow-up.

8. We tested the sensitivity of our results to alternative model specifications. We excluded the managed care competition variables from the model to test whether the effects of managed care penetration were sensitive to the inclusion of this variable. We found that removing the managed care competition variable generally has little effect on our estimates of the effects of managed care penetration on the process of care. One exception is the model of cardiac catheterization within 30 days. In this case, the point estimate is similar but the standard errors increase, resulting in the effects not being statistically significant at $p \leq .05$. For the models of cost and outcomes, removal of the managed care competition variables has little effect on the estimates of the effects of managed care penetration. We also reestimated the models including region fixed effects and found that results are generally robust to the inclusion of region fixed effects.

\section{REFERENCES}

Altman, D., D. Cutler, and R. Zeckhauser. 2003. "Enrollee Mix, Treatment Intensity, and Cost in Competing Indemnity and HMO Plans." Journal of Health Economics 22 (1): 23-45.

Baker, L. 1997. "The Effect of HMOs on Fee-for-Service Health Care Expenditures: Evidence from Medicare." Journal of Health Economics 16 (4): 453-81.

. 1999. "Association of Managed Care Market Share and Health Expenditures for Fee-for-Service Medicare Patients." Journal of the American Medical Association 28 (15): 432-7.

- 2001. "Managed Care and Technology Adoption in Health Care: Evidence from Magnetic Resonance Imaging." Journal of Health Economics 20 (3): 395-421.

Baker, L., and M. Brown. 1999. "Managed Care, Consolidation among Health Care Providers, and Health Care: Evidence from Mammography." Rand Journal of Economics 30 (2): 351-74. 
Baker, L., and C. Phibbs. 2000. "Managed Care, Technology Adoption, and Health Care: The Adoption of Neonatal Intensive Care." Working Paper 7883. Cambridge, MA: National Bureau of Economic Research.

Bamezai, A., J. Zwanziger, G. A. Melnick, and J. M. Mann. 1999. "Price Competition and Hospital Cost Growth in the United States (1989-1994)." Health Economics 8 (3): 233-43.

Chernew, M. 1995. "The Impact of Non-IPA HMOs on the Number of Hospitals and Hospital Capacity." Inquiry 32 (2): 143-54.

Cutler, D. M., M. McClellan, and Newhouse. 2000. "How Does Managed Care Do It?" Rand Journal of Economics 31 (3): 526-48.

Ellerbeck, E., S. Jencks, M. Radford, T. Kresowik, F. Timothy, A. Craig, J. Gold, H. Krumholz, and R. Vogel. 1995. "Quality of Care for Medicare Patients with Acute Myocardial Infarction. A Four-State Pilot Study from the Cooperative Cardiovascular Project." Journal of the American Medical Association 273 (19): 1509-14.

Ellis, R. P., and T. G. McGuire. 1993. "Supply-Side and Demand-Side Cost Sharing in Health Care." Journal of Economic Perspectives 7 (4): 135-51.

Escarce, J., D. Polsky, G. Wozniak, and P. Kletke. 2000. "HMO Growth and the Geographical Redistribution of Generalist and Specialist Physicians, 19871997." Health Services Research 35 (4): 825-48.

Escarce, J., D. Polsky, G. Wozniak, M. Pauly, and P. Kletke. 1998. "Health Maintenance Organization Penetration and the Practice Location Choices of New Physicians: A Study of Large Metropolitan Areas in the United States." Medical Care 36 (11): 1555-66.

Gaskin, D. 1997. "The Impact of Health Maintenance Organization Penetration on the Use of Hospitals That Serve Minority Communities." Medical Care 35 (12): 1190203.

Gaskin, D., and J. Hadley. 1997. "The Impact of HMO Penetration on the Rate of Hospital Cost Inflation, 1985-1993.” Inquiry 34 (3): 205-16.

Gaynor, M., J. B. Rebitzer, and J. T. Lowell. 2001. “Incentives in HMOs.” Working paper. Cambridge, MA: National Bureau of Economic Research.

Glied, S., and J. G. Zivin. 2002. "How Do Doctors Behave When Some (but Not All) of Their Patients Are in Managed Care." Journal of Health Economics 21 (2): 337-53.

Goldberg, L. G., and W. Greenburg. 1981. "The Determinants of HMO Enrollment and Growth." Health Services Research 16 (4): 421-38.

Hadley, J., J. Mitchell, D. Sulmasy, and M. Bloche. 1999. "Perceived Financial Incentives, HMO Market Penetration, and Physicians' Practice Styles and Satisfaction." Health Services Research 34 (1): 307-21.

Heidenreich, P. A., M. McClellan, C. Frances, and L. C. Baker. 2002. "The Relation between Managed Care Market Share and the Treatment of Elderly Fee-forService Patients with Myocardial Infarction.” American Journal of Medicine 112 (3): 176-82.

International Classification of Diseases (ICD) 1991. Los Angeles: Practice Management Information Corp.

Krumholz, H., J. Chen, Y. Chen, Y. Wang, and M. Radford. 2001. "Predicting OneYear Mortality among Elderly Survivors of Hospitalization for an Acute 
Myocardial Infarction: Results from the Cooperative Cardiovascular Project.” Journal of the American College of Cardiologists 38 (2): 453-9.

Krumholz, H., M. Radford, E. Ellerbeck, J. Hennen, T. Meehan, M. Petrillo, Y. Wang, T. Kresowik, and S. Jencks. 1995. "Aspirin in the Treatment of Acute Myocardial Infarction in Elderly Medicare Beneficiaries." Circulation 92 (10): 2841-7.

Ma, C. A. 1994. "Health Care Payment Systems: Cost and Quality Incentives." Journal of Economics and Management Strategy 3 (1): 93-112.

Ma, C. A., and T. G. McGuire. 1997. "Optimal Health Insurance and Provider Payment." American Economic Review 87 (4): 685-704.

_ 2002. "Network Incentives in Managed Health Care." Journal of Economics and Management Strategy 11 (1): 1-35.

Melnick, G. A., J. Zwanziger, A. Bamezai, and R. Pattison. 1992. "The Effects of Market Structure and Bargaining Position on Hospital Prices." Journal of Health Economics 11 (3): 217-33.

Miller, R., and H. Luft. 1997. "Does Managed Care Lead to Better or Worse Quality of Care." Health Affairs 16 (5): 7-25.

Newhouse, J. P. 1996. "Reimbursing Health Plans and Health Providers: Efficiency in Production versus Selection." Journal of Economic Literature 34 (3): 1236-63.

Pauly, M. V. 1998. "Managed Care, Market Power, and Monopsony." Health Services Research 33 (5, part 2): 1439-60.

Phelps, C. E. 1992. "Diffusion of Information in Medical Care." Journal of Economic Perspectives 6 (3): 23-42.

Polsky, D., P. Kleteke, G. Wozniak, and J. Escarce. 2000. "HMO Penetration and the Geographic Mobility of Practicing Physicians." Journal of Health Economics 19 (5): 793-809.

Polsky, D., and S. Nicholson. 2003. "Why Are Managed Care Plans Less Expensive: Risk Selection, Utilization, or Reimbursement?" Journal of Risk and Insurance. In Press.

Porell, F., and S. Wallack. 1990. "Medicare Risk Contracting: Determinants of Market Entry." Health Care Financing Review 12 (2): 17-30.

Remler, D. K., K. Donelan, R. J. Blendon, G. D. Lundberg, L. L. Leape, D. R. Calkins, K. Binns, and J. P. Newhouse. 1997. "What Do Managed Care Plans Do to Affect Care? Results from a Survey of Physicians." Inquiry 34 (3): 196-204.

Robinson, J. C. 1991. "HMO Market Penetration and Hospital Cost Inflation in California." Journal of the American Medical Association 266 (19): 2719-29.

_ 1996. "Decline in Hospital Utilization and Cost Inflation Under Managed Care in California." Journal of the American Medical Association 276 (13): 1060-4.

Rogers, W. H. 1993. "Regression Standard Errors in Clustered Samples." STATA Technical Bulletin 13: 19-23.

Rouleau, J., L. Moye, M. Pfeffer, J. Arnold, V. Bernstein, T. Cuddy, G. Dagenais, E. Geltman, S. Goldman, D. Gordon, P. Hamm, M. Klein, G. A. Lamas, J. McCans, P. McEwan, F. J. Menapace, J. O. Parker, F. Sestier, B. Sussex, and E. Braunwald. 1993. "A Comparison of Management Patterns after Acute Myocardial Infarction in Canada and the United States: The SAVE Investigators." New England Journal of Medicine 328 (11): 779-84. 
Welch, W. 1994. HMO Market Share and Its Effects on Local Medicare Costs: HMOs and the Elderly, edited by H. Luft, pp. 231-49. Ann Arbor, MI: Health Administrative Press.

White, H. 1980. "A Heteroskedasticity-Consistent Covariance Matrix Estimator and a Direct Test for Heteroskedasticity.” Econometrica 48 (4): 817-38.

Wickizer, T. M., and D. Lessler. 2002. "Utilization Management: Issues, Effects, and Future Prospects." Annual Review of Public Health 23: 233-54. 